\title{
AUMENTO DO DESEMPENHO DE COLETORES SOLARES COM A ADIÇÃO DE NANOFLUIDOS
}

Julia Luise Melo Carneiro1; Vinícius Mariani Lenart"1; Rozane de Fátima Turchiello Gómez; Sergio Leonardo Gómez²

1 Universidade Tecnológica Federal do Paraná; Ponta Grossa/PR; julialuisec@gmail.com

${ }^{2}$ Universidade Estadual de Ponta Grossa; Ponta Grossa/PR

Resumo: O impacto dos combustíveis fósseis, assim como aspectos ambientais, motivaram pesquisas a respeito de fontes alternativas de energia. É possível usar nanofluidos para gerar calor na presença de radiação eletromagnética. Esta característica pode ser utilizada para absorver a radiação solar eficientemente. $O$ objetivo deste trabalho é comparar os resultados experimentais da aplicação de nanofluido em um coletor solar com o modelo convencional sob condições similares. Observou-se que os nanofluidos podem ser utilizados para atingir um desempenho equiparado com os convencionais, sendo que a absorção de luz é proporcional à concentração de nanopartículas e não limitada pela cor no caso dos convencionais.

Palavras-Chave: energia renovável; coletor solar; nanofluidos.

\section{INCREASING SOLAR COLLECTORS PERFORMANCE WITH NANOFLUIDS}

\begin{abstract}
The impact of fossil fuels as well as environmental aspects motivated researches on renewable energy source. It's possible to use nanofluids to generate heat in the presence of electromagnetic radiation. This characteristic can be utilized to efficiently absorb solar radiation. The aim of this communication is to compare the experimental results nanofluid application in a solar collector with conventional model under similar conditions. It was observed that nanofluids can be used to achieve performance comparable to conventional ones, with light absorption being proportional to nanoparticle concentration and it is not limited by color as in the case of conventional ones.
\end{abstract}

Keywords: renewable energy; solar collector; nanofluids. 


\section{INTRODUÇÃO}

O aumento de indícios de problemas ambientais ocorre devido a diversos fatores ligados ao crescimento do impacto causado pelas atividades humanas. Dentre essas adversidades, a elevação da emissão de dióxido de carbono na atmosfera causado pela queima de combustíveis fósseis contribui, significativamente, com o aquecimento global. Uma vez que a energia é considerada uma razão de extrema importância na geração de riqueza e no crescimento econômico, são necessárias estratégias de longo prazo que visem um desenvolvimento sustentável. Dentre tais ações, investimentos em recursos energéticos renováveis podem ser uma solução eficaz, a exemplo da energia provinda do Sol. A principal maneira de transformar a energia da radiação solar em energia térmica é por meio de coletores solares. Esses tipos de trocadores de calor, ao realizarem a conversão, transferem o calor para um fluido - em geral ar, água ou óleo [1].

Nanopartículas (Nps) de metais nobres possuem alta absorção óptica dentro do comprimento espectral de máxima irradiação do Sol, como apresentado na Figura 1, podendo ser utilizadas para aprimorar o desempenho de tais sistemas [2]. Dentre os efeitos fototérmicos, a geração de calor desses sistemas coloidais ocorre devido à absorção da radiação eletromagnética e, posteriormente, à transferência de calor da Np para o fluido. No caso de nanoesferas de metais nobres, como o ouro e a prata, a liberação de calor torna-se mais forte devido ao movimento coletivo dos elétrons livres, chamado de ressonância de plasmon de superfície, o qual se manifesta na região visível do espectro eletromagnético [3].

Figura 1. Intensidade do espectro experimental de absorção de nanopartículas metálicas com o espectro de luz visível e irradiância espectral do sol (em cinza) [4].

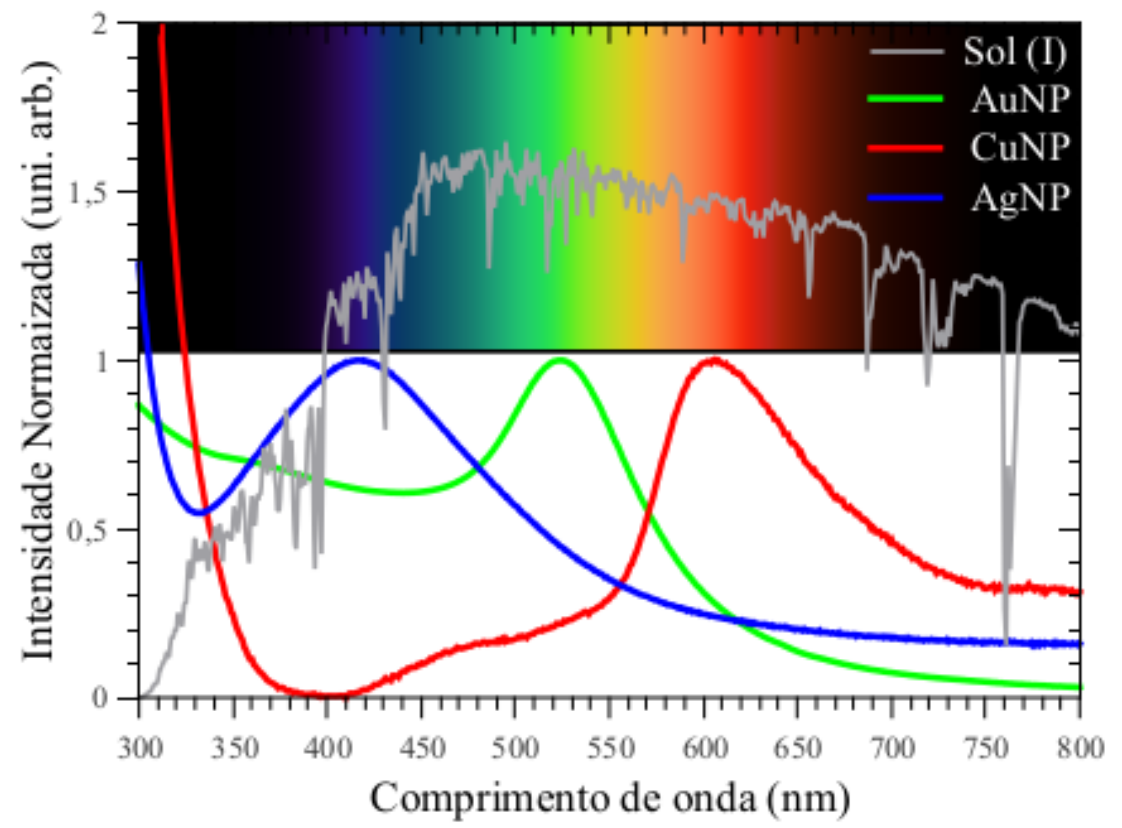

Nesse sentido, pesquisas neste campo vêm constatando que o uso nanofluidos pode aumentar a eficiência de sistemas solares. Taylor et al. [5] realizaram uma comparação de um dispositivo térmico convencional com outro utilizando 
nanomateriais no fluido base. Em consequência dos resultados obtidos, além da utilização desse fluido aumentar em $10 \%$ a eficiência do coletor, os autores concluíram que o emprego de grafite em escala nanométrica com fração volumétrica de aproximadamente $0,001 \%$ no receptor de uma torre de energia solar no Arizona poderia gerar um lucro de US $\$ 3,5$ milhões a mais por ano [5]. Semelhantemente, Khullar et al. [6] investigaram teórica e experimentalmente a utilização de Nps de alumínio com um volume de $0,05 \%$ suspensos em Therminol VP-1 em coletores solares parabólicos. Eles descobriram que a eficiência térmica corresponde a um valor cerca de 5 a 10\% maior em comparação com modelos convencionais sob as mesmas condições climáticas [6]. Neumann et al. também evidenciaram a capacidade de água com nanopatículas gerarem vapor devido à interação com a luz, sem a necessidade de aquecer o volume do fluido permitindo importantes aplicações solares compactas, como a esterilização de resíduos e instrumentos cirúrgicos em locais com poucos recursos [7].

Esse processo de aquecimento é relacionado com dois mecanismos de interação entre as Nps. O primeiro deles, o efeito acumulativo, surge pela adição de fluxos de calor gerados individualmente pelas partículas e é descrito pela somatória da equação de termo difusão. Com isso, quanto mais Nps, mais forte é o aumento da temperatura no sistema. Já o segundo corresponde ao efeito da interação Coulombiana, no qual Nps impulsionadas opticamente interagem entre si através dos campos elétricos e o calor resultante depende tanto da distância entre elas quanto dos arranjos formados. Essa quantidade de calor gerada é diferente da provinda do efeito acumulativo, já que a dissipação total de calor pode aumentar ou diminuir dependendo da polarização da luz [3].

Dessa forma, este trabalho explora o aspecto sinérgico de nanofluidos de ouro e prata no desenvolvimento de aquecedores solar de água mais eficientes e que possuem outras vantagens em relação aos atuais. Na secção 2 descrevemos a metodologia em duas partes: i) a teórica cujo foco é determinar as perdas totais de calor de uma $\mathrm{Np}$ e ii) a experimental que consiste na síntese desses materiais, construção de dois aquecedores solares e um módulo de controle e aquisição de dados. Discutimos os resultados na secção 3 e por fim na 4 mostramos nossas conclusões e perspectivas.

\section{METODOLOGIA}

O trabalho ocorreu em duas etapas. Na primeira realizou-se um estudo teórico composto por simulações, utilizando o software COMSOL 5.4. Já na segunda, a análise experimental consistiu na síntese das nanopartículas de ouro e prata, na construção do aparato de aquecimento, na preparação do arranjo eletromecânico e na coleta de dados.

\subsection{Procedimento teórico}

Simulou-se, no software COMSOL 5.4, o cálculo do espalhamento de uma onda de luz de 300 a 700 nanômetros de uma nanoesfera de ouro e prata com raios de 14 e 54 nanômetros, respectivamente. Calculamos através do método dos elementos finitos a intensidade de absorção em função do comprimento de onda, no 
caso em que uma onda viaja na direção x positiva com o campo elétrico polarizado ao longo do eixo z. Também adicionou-se uma variável para as perdas totais de calor na esfera, a qual foi calculada como um volume integral das perdas resistivas e comparada com os resultados experimentais.

\subsection{Procedimento experimental}

Em um primeiro momento, sintetizamos os nanofluidos através do método de redução química. Após isso, um aparelho experimental para medir a temperatura dos aquecedores foi elaborado com o intuito de comparar um modelo contendo nanofluido e outro contendo água.

\subsubsection{Síntese das nanopartículas de ouro}

A síntese das Nps metálicas foi realizada seguindo método adaptado de Turkevich [8] que passa pela redução química do sal metálico, nucleação, crescimento e pela estabilização por meio de um agente surfactante. Para a síntese do ouro e prata, foram utilizados $20 \mathrm{~mL}$ de uma solução de $1,0 \mathrm{mM}$ de cloreto de ouro ácido trihidratado $\left(\mathrm{HAuCl}_{4} \cdot 3 \mathrm{H}_{2} \mathrm{O}\right.$ - Vetec) e nitrato de prata $\left(\mathrm{AgNO}_{3}\right.$ - Synth) como precursor, respectivamente. $2,0 \mathrm{~mL}$ de uma solução aquosa de $1 \%$ de citrato de sódio diidratado $\left(\mathrm{Na}_{3} \mathrm{C}_{6} \mathrm{H}_{5} \mathrm{O}_{7} \cdot 2 \mathrm{H}_{2} \mathrm{O}\right.$ - Synth) como agente redutor e surfactante. Inicialmente, colocouse os $20 \mathrm{~mL}$ do sal em questão em um Erlenmeyer e aqueceu, sob agitação magnética, até iniciar o processo de ebulição. Colocou-se um vidro relógio sobre o frasco para evitar a perda de água por evaporação. Com a solução em ebulição e sob agitação, foi adicionado $2 \mathrm{~mL}$ de uma solução de citrato de sódio. Logo, a solução coloidal se forma, gradualmente, à medida que o citrato de sódio reduz e apresenta uma cor vermelho rubi para o ouro e amarelo ouro para prata. Por fim, retirou-se o frasco do agitador magnético para armazenar em resfriamento. Para o uso nos aquecedores, misturamos os coloides de ouro e prata em uma relação de 50:50. O tamanho e forma das Nps foram aferidos por microscopia eletrônica de transmissão (JEOL JEM 1200EX-II).

\subsubsection{Construção do aparato de aquecimento}

Para a construção dos painéis aquecedores solares de água foram necessários dois suportes de madeira quadrados com 60 centímetros de lado, 5 metros de mangueira de poliuretano (PU) transparente e preto com $4 \mathrm{~mm}$ de diâmetro interno e $6 \mathrm{~mm}$ de diâmetro externo, manta térmica de alumínio. Uma representação esquemática é apresentada na Figura 2. As mangueiras foram dispostas em um padrão circular sobre a manta térmica de alumínio. 
Figura 2. Diagrama dos aquecedores solares durante a realização do experimento.

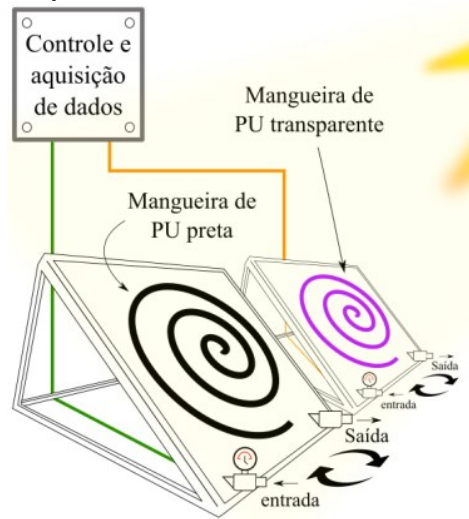

\subsubsection{Preparação do arranjo eletromecânico e aquisição de dados}

Na montagem do sistema eletromecânico para medição de temperatura foram utilizadas uma placa de processamento Arduino Uno R3, um módulo relé com 2 canais, dois Termopares tipo $\mathrm{K}$ acoplados a dois módulos de leitura Max6675, um módulo de cartão SD para gravar os dados e duas bombas d'água.

Os fluidos eram inseridos nas mangueiras que eram conectadas às bombas d'água. Em seguida as bombas eram acionadas para executar a sangria do sistema a fim de eliminar as bolhas de ar.

O protocolo de medidas estabelecido consiste em uma média de 5 medidas de temperatura a cada intervalo de 30 segundos, seguidos do acionamento das bombas d'água por um intervalo de 0,5 segundos.

\section{RESULTADOS E DISCUSSÃO}

A Figura 3 mostra as imagens de microscopia eletrônica de transmissão das nanopartículas. Como resultado, temos a verificação do aspecto esférico e a distribuição de tamanhos de $(14 \pm 2) \mathrm{nm}$ e $(54 \pm 15) \mathrm{nm}$ para as partículas de ouro e prata respectivamente.

Figura 3. Imagens por microscopia eletrônica de nanopartículas de a) ouro e b) prata.
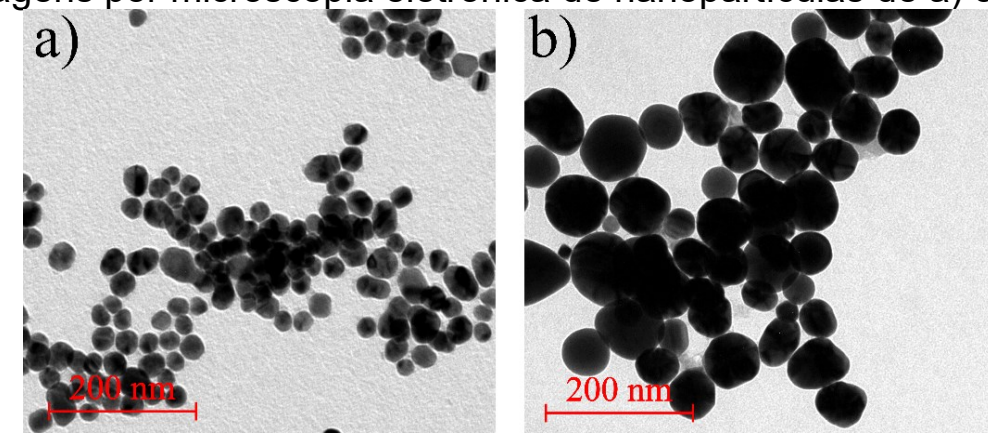

Essa informação é inserida nos dados de entrada da simulação. Como esperado, visto os dados da Figura 1, o cálculo da absorção das partículas de prata e ouro revelou absorções máximas nas regiões do azul e verde, respectivamente. Porém, podemos observar na Figura 4 que a contribuição das esferas de prata no aquecimento é maior, considerando o comprimento de onda de máxima perda. Isso está associado ao tamanho da partícula. Contudo, devemos lembrar que o máximo 
de irradiância espectral do sol se encontra na região que as Nps de ouro absorvem. Então mesmo que as Nps de prata possam contribuir mais, ainda existe uma maior intensidade de luz vindo para as Nps de ouro, o que causa um efeito compensatório. No entanto, as partículas podem ser modificadas, alterando as proporções na síntese, para melhor se adequar ao espectro do sol. Outro fator a ser considerado é a proporção de cada coloide na mistura. Essa relação deve otimizar o espectro de absorção da mistura com a convolução de comprimentos de onda emitidos pelo sol. Neste trabalho nós utilizamos a proporção 50:50, porém é possível melhorar esse parâmetro.

Figura 4. Perdas totais de calor nas nanoesferas de ouro e prata, calculadas como um volume integral das perdas resistivas.

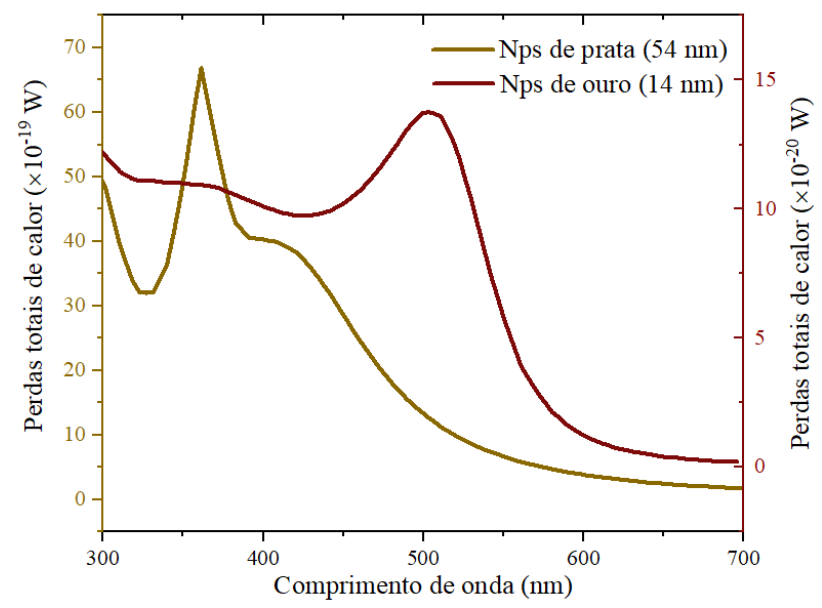

Os melhores sistemas aquecedores são coloridos de preto para o aumento da absorção da luz solar. Nessa etapa comparamos o quanto a coloração da mangueira influencia na absorção. As informações da Figura 5 correspondem aos dados da temperatura do fluido no aparato que, para essa medida, utilizou somente água em ambas as mangueiras (preta e transparente). A diferença entre as duas curvas revela a contribuição da mangueira preta na absorção. Evidentemente, o experimento depende de condições climáticas favoráveis. Os ícones sobre o gráfico são dados referentes ao clima, obtidos pela estação meteorológica do SIMEPAR [9]. Naturalmente, a água na mangueira preta atingiu temperaturas mais elevadas.

Figura 5. Comparação da energia térmica transferida usando água nas duas configurações.

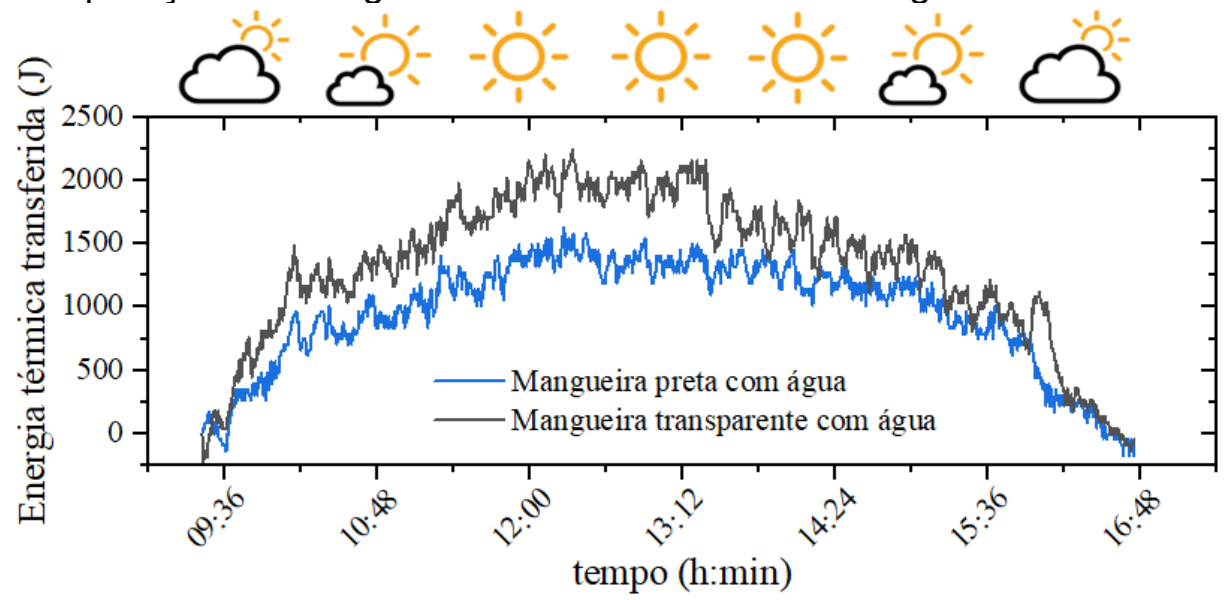


É interessante ressaltar que a água presente na mangueira transparente atingiu valores mais baixos, porém consideráveis. Isso se deve a grande banda de absorção que a água tem na região do infravermelho [7].

Realizando o mesmo experimento em outro dia, as condições climáticas mudam, porém como estamos fazendo uma medida comparativa, obtemos um resultado relativo. Dessa forma, a Figura 6 apresenta os dados da energia térmica transferida do nanofluido na mangueira transparente e da água na preta.

Figura 6. Comparação da energia térmica transferida usando nanofluido na magueira transparente e água na mangueira preta.

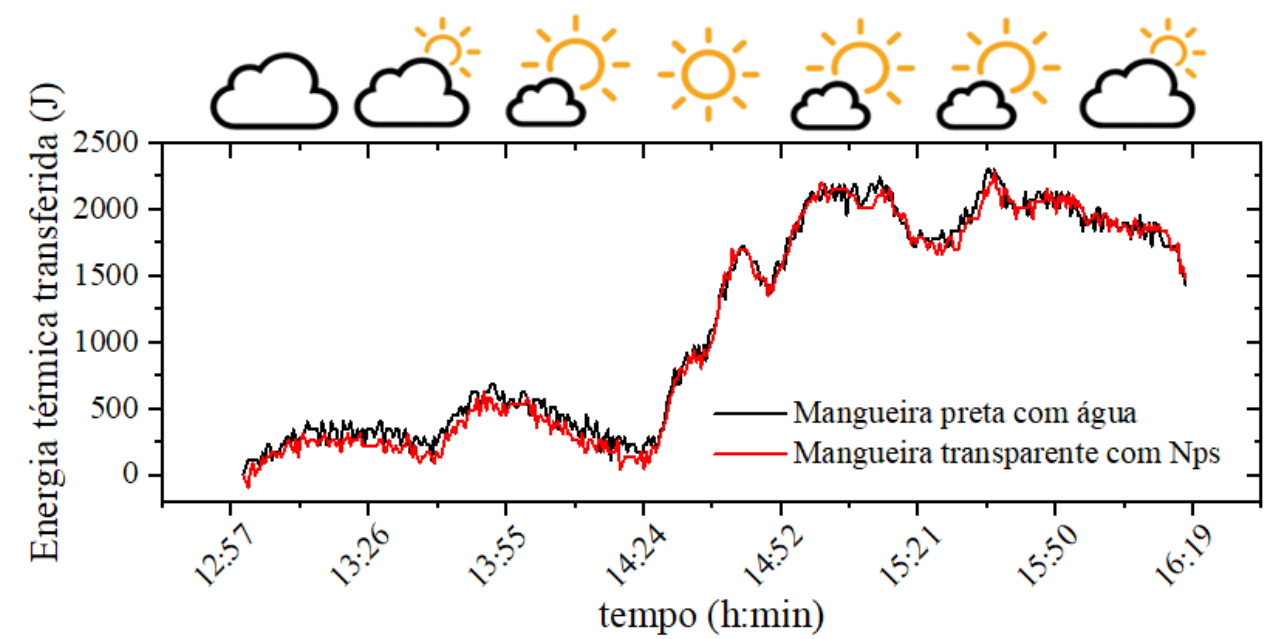

Diferentemente do experimento anterior, a luz que atravessa a mangueira transparente atinge as Nps que transferem o calor diretamente para o fluido. Como podemos observar, considerando a montagem do experimento realizada, a energia térmica transferida no caso da mangueira preta e para o nanofluido na mangueira transparente se equivalem. Isso indica um resultado positivo, considerando o fato de que a quantidade de luz absorvida pela mangueira preta é sempre a mesma, ao passo que se aumentarmos a concentração de Nps na mangueira transparente, a absorção pode crescer ainda mais, aumentando assim o desempenho do aquecedor solar.

\section{CONCLUSÃO}

De forma geral, conseguimos verificar as perdas resistivas de nanopartículas de prata e ouro e argumentar sobre sua influência no aquecimento segundo a irradiância espectral do sol em função do comprimento de onda. Construímos dois sistemas de painéis de aquecimento solar de água que adquire a temperatura e movimenta o fluido em intervalos de tempo predeterminado. Mostramos que Nps podem ser utilizadas para aumentar a eficiência da energia térmica transferida e que o aumento pode estar limitado pela concentração de Nps na solução. A perspectiva é de que sistemas de aquecimento com Nps possam ser adaptados aos telhados, pois são translúcidos, isso reuniria as funcionalidades de aquecedor solar e de iluminação natural. 


\section{Agradecimentos}

À UTFPR. Ao laboratório do Grupo de Fenômenos Fototérmicos em Fluidos Complexos (GFFFC) da Universidade Estadual de Ponta Grossa- UEPG. Ao Complexo de Laboratórios Multiusuários (C-LABMU), da Universidade Estadual de Ponta Grossa- UEPG. V. M. Lenart agradece à CAPES pela bolsa (PNPD 88882.316859/2019-01).

\section{REFERÊNCIAS}

${ }^{1}$ KALOGIROU, S. A. Solar Energy Engineering: Processes and Systems. Oxford: Elsevier, 2009.

2 MAHIAN, O. et al. A review of the applications of nanofluids in solar energy. International Journal of Heat and Mass Transfer, v. 57, p. 582-594, 2013.

${ }^{3}$ GOVOROV, A. O. et al. Generating heat with metal nanoparticles. Nano Today, v. 2, p. 30-38, 2007.

${ }^{4}$ LENART, V. M. Estudo das propriedades ópticas e de transporte térmico do ouro coloidal em cristais líquidos liotrópicos. Tese (Doutorado) - Universidade Estadual de Ponta Grossa, Ponta Grossa, 2015.

${ }^{5}$ TAYLOR, R. A. et al. Applicability of nanofluids in high flux solar collectors. Journal of Renewable and Sustainable Energy, 2011.

${ }^{6}$ KHULLAR, V. et al. Solar energy harvesting using nanofluids-based concentrating solar collector. Journal of Nanotechnology in Engineering and Medicine, v. 3, 2012.

${ }^{7}$ NEUMANN, O. et. al. Solar vapor generation enabled by nanoparticles, ACS Nano, v. 7,2013

${ }^{8}$ TURKEVICH, J. et al. A study of the nucleation and growth processes in the synthesis of colloidal gold. Discussions of the Faraday Society, v. 11, 1951.

${ }^{9}$ SIMEPAR. Disponível em: <http://www.simepar.br/>. Acesso em: 13 agosto. 2019. 